\title{
INTERSTITIAL LUNG DISEASE AS THE FIRST MANIFESTATION OF RHEUMATOID ARTHRITIS: A CASE REPORT
}

Izabela Zarnowski Passos ${ }^{1, \star}$, Ana Maria São Thiago Santiago Bez ${ }^{1}$, Christiane Cota Vieira1, Deborah Lobato Guimarães ${ }^{1}$, lara Mateus Marçal ${ }^{1}$, Lucas Leonardo de Castro Borges ${ }^{1}$, Luiz Severiano Ribeiro ${ }^{1}$, Rejane Pinheiro Damasceno ${ }^{1}$

1.Instituto de Previdência dos Servidores do Estado de Minas Gerais, Belo Horizonte (MG), Brazil.

*Corresponding author: izabelazarnowskipassos@gmail.com

\section{BACKGROUND}

Rheumatoid arthritis is an autoimmune, chronic and systemic disease with no defined etiology, that primarily affects synovial joints. Lung and pleura are also common sites of extraarticular involvement. Manifestation of interstitial lung disease on RA-onset is a major concern due to its potential seriousness and therapeutic challenge.

\section{CASE REPORT}

A 51-year-old female, started in August 2020 with dyspnea (mMRC class IV), and sought care in an emergency room. The diagnostic suspicion was SARS-CoV-2 virus infection (COVID-19). Despite having a negative molecular test, a chest tomography was performed and showed multiple ground-glass opacifications. The patient remained hospitalized for a few days and after being discharged from hospital, she maintained severe dyspnea and started with intense myalgia and weakness in the shoulder girdle, being referred by the internal medicine team for rheumatologic evaluation. In the first evaluation, the diagnostic hypothesis of polymyalgia rheumatica was raised, with high-dose prednisone being prescribed and initial diagnostic work up. The patient returned with lab test results that showed positive rheumatoid factor and ACPA (116.2 and 5.9, respectively), in addition to having developed arthritis in some proximal interphalangeal joints, then was established the diagnose of rheumat id arthritis with interstitial lung disease. Treatment with methotrexate was started; however, after 2 months the patient had worsened lung function. A comprehensive review of the literature was carried out and it was decided to start treatment with rituximab, with good therapeutic response.

\section{CONCLUSION}

The best treatment for interstitial lung disease secondary to rheumatoid arthritis is yet to be established. Drug pneumotoxicity raises concern, but current evidence suggests a protector factor in RA patients submitted to methotrexate treatment. Some studies show that the use of glucocorticoids and other biologic or synthetic DMARDs can be beneficial, especially in young patients with usual interstitial pneumonia and symptomatic patients. In an article published in 2020 in Rheumatology, it was concluded that patients with interstitial lung disease who were treated with rituximab apparently had lower mortality rates compared to patients treated with anti-TNF, although the difference did not reach statistical significance.

\section{KEYWORDS}

Rheumatoid arthritis, Interstitial lung disease, Rituximab. 